\title{
Uplink Capacity Estimation and Enhancement in WCDMA Network
}

\author{
Fadoua Thami Alami \\ Abdelmalek Ess aadi University, Morocco \\ E-mail: fadouaalami@yahoo.fr \\ Noura Aknin \\ Abdelmalek Essaadi University, Morocco \\ E-mail:aknin@ieee.org \\ Ahmed El Moussaoui \\ Abdelmalek Essaadi University, Morocco \\ E-mail: elmoussaoui@uae.ma
}

\begin{abstract}
Uplink planification in a WCDMA network consists of estimating the maximum capacity that a cell can support, by using the quality of service equation designed by $E_{b} / N_{0}$. We are interested in this work on two different scenarios: an isolated cell and multiple cells. This capacity is adversely affected by interferences due to own mobile stations and to others belonging to neighboring cells. In order to enhance capacity and minimize the blocking probability of new requests in the cell, we have proposed a Freeing Resources algorithm which consists of releasing some mobile stations in the handover area with the overloaded cell. This algorithm is based on freeing 1, 2 and 3 mobile stations of $12.2 \mathrm{kbps}$ and 1 mobile station of $64 \mathrm{kbps}$.
\end{abstract}

Index Terms - WCDMA, Uplink, Maximu m Capacity, Multi-Service Network, Isolated Cell, Multiple Cells, Interferences, Blocking Probability

\section{Introduction}

In WCDMA cell, all users share the same bandwidth. Thus, each new connection increases the interference level for the ongoing connections, by affecting their quality of service expressed in terms of $E_{b} / N_{O}$. In addition, interference due to mobile stations (MSs) belonging to neighboring cells affects negatively the maximum cell capacity, and increases the requirements of mobile stations in terms of transmission power.

In this paper, we evaluate the effect of other-to-own-cell interference on Uplink capacity and we propose an algorithm to reduce the blocking probability of the new requests.

The remaining of this paper is organized as follows. In section 2 we intend to show, the tradeoff between capacity and coverage on the basis of the quality of service equation, and to highlight the effect of other-to-own-cell interference on different parameters in Uplink direction. In this context, we will study the Uplink capacity in the case of two scenarios: single cell and multiple cells, on the basis of the $E_{b} / N_{0}$, the cell loading factor $\eta_{U L}$, as well as the Noise Rise (NR) supported by the cell. A comparison between mobile station transmission power requirements for both scenarios will be also presented in the same section. The section 3 will be devoted to an algorith m of Freeing Resources. This algorithm aims to release some connections in the handover area, in order to increase the cell capacity and reduce the blocking probability of new requests seeking access to the network. This algorith $\mathrm{m}$ will be applied for two values of $f_{U L}$ in order to show the effect of other-to-own-cell interfe rence on the algorithm efficiency. Section 4 presents the results obtained from the simulation. And finally in, section 5, some conclusions are provided.

II. Uplink Capacity and Coverage Es timation in a Multi-Service Network

\subsection{Mobile Station Trans mission Power Expression} in the Case of an Isolated Cell

The minimum $E_{b} / N_{0}$ required for a user $(i)$ in the Uplink direction, in the case of an isolated cell, can be expressed by [1,7]:

$$
\left.\frac{E_{b}}{N_{0}}\right)_{i}=\frac{W}{R_{i}} \frac{P_{r, i}}{P_{N}+P_{o w n}-P_{r, i}}
$$

And: 


$$
P_{\text {own }}=\sum_{i=1}^{N} P_{r, i}
$$

where:

- $P_{r, i}$ is the Node B received power from the user( $\left.i\right)$.

- $N$ is the number of user in the cell.

- $P_{\text {own }}$ is the total own-cell interferences received power at the Node B. It depends on the distribution of user in the cell and propagation conditions.

- $P_{N}$ is the thermal noise power at the Node B.

From (1), the minimu $\mathrm{m}$ required received power for a user $(i)$ at the Node B, by taking into account the activity factor $v_{i}$, is expressed as:

$$
P_{r, i}=\frac{P_{N}+P_{o w n}}{\frac{W}{\left(\frac{E_{b}}{N_{0}}\right)_{i} R_{i} v_{i}}+1}
$$

Therefore, from (2) and (3), the total own-cell interferences received power at the Node B is given by:

$$
P_{\text {own }}=\frac{P_{N} \sum_{i=1}^{N} \frac{1}{\frac{W}{\left.\frac{E_{b}}{N_{0}}\right)_{i} R_{i} v_{i}}+1}}{1-\sum_{i=1}^{N} \frac{1}{\frac{W}{\left.\frac{E_{b}}{N_{0}}\right)_{i} R_{i} v_{i}}+1}}
$$

Consequently, (3) can be rewritten as:

$$
P_{r, i}=
$$

$$
\frac{P_{N}}{\left(\frac{W}{\left.\frac{E_{b}}{N_{0}}\right)_{i} R_{i} v_{i}}+1\right)\left(1-\sum_{i=1}^{N} \frac{1}{\frac{W}{\left.\frac{E_{b}}{N_{0}}\right)_{i} R_{i} v_{i}}+1}\right)}
$$

Therefore, the required transmitted power at the Node B is expressed as:

$$
\begin{gathered}
P_{t, i}= \\
\left(\frac{W}{\left.\frac{E_{b}}{N_{0}}\right)_{i} R_{i} v_{i}}+1\right)\left(1-\sum_{i=1}^{N} \frac{1}{\frac{W}{\left.\frac{E_{b}}{N_{0}}\right)_{i} R_{i} v_{i}}+1}\right)
\end{gathered}
$$

\subsection{Uplink Cell Capacity in the Case of an Isolated Cell}

The Uplink capacity depends on the $N R$ factor generated by users, belonging to the serving cell. During the dimensioning phase of a cellular radio mobile network, an operator must limit the maximum cell load respecting a $N R$ threshold.

\subsubsection{Noise Rise and cell loading factor expressions}

Noise Rise factor is defined as the ratio between the Node B total received power, $P_{t o t}$, and the thermal noise power of the Node B, $P_{N}[2-4]$ :

$$
N R=\frac{P_{t o t}}{P_{N}}
$$

In the case of an is olated cell, $P_{t o t}$ expression is given as:

$$
P_{\text {tot }}=P_{\text {own }}+P_{N}
$$

Thus:

$$
N R=\frac{P_{o w n}+P_{N}}{P_{N}}
$$

If the cell is $100 \%$ loaded, the $N R$ factor tends to an infinite value. Therefore, the relationship between $N R$ and the cell loading factor is:

$$
N R=\frac{1}{1-\eta_{U L}}
$$

Therefore:

$$
\eta_{U L}=\frac{P_{o w n}}{P_{o w n}+P_{N}}
$$

Consequently: 


$$
\eta_{U L}=\sum_{i=1}^{N} \frac{1}{\frac{W}{\left.\frac{E_{b}}{N_{0}}\right)_{i} R_{i} v_{i}}+1}
$$

The Uplink cell loading factor must verify the following condition:

$$
\sum_{i=1}^{N} \frac{1}{\frac{W}{\left.\frac{E_{b}}{N_{0}}\right)_{i} R_{i} v_{i}}+1}<1
$$

Therefore, for $N$ users activating the same service, the Uplink capacity is limited to the following inequality:

$$
N<\frac{W}{\left.\frac{E_{b}}{N_{0}}\right)_{i} R_{i} v_{i}}+1
$$

So, if $\eta_{U L}$ approaches to 1 , the system reaches its pole capacity and becomes unstable. The total received power at the Node B becomes very larger than the thermal noise power, and decoding process at the Node B is no longer possible. We must therefore define a maximum value $\eta_{U L_{-} \text {max }}$ that the cell loading factor must not exceed:

$$
\eta_{U L} \leq \eta_{U L_{-} \max }
$$

\subsubsection{Coverage and capacity tradeoff in the case of an isolated cell}

Equation (6) can be expressed as:

$$
P_{t, i}=L_{i} \frac{P_{N}}{\left(\frac{W}{\left.\frac{E_{b}}{N_{0}}\right)_{i} R_{i} v_{i}}+1\right)\left(1-\eta_{U L}\right)}
$$

From this expression we deduce that, when the cell load increases, the required transmission power for the MS will be important. In addition, since the available power at the MS is limited, the cell loading factor on the Uplink direction must be monitored to ensure the coverage provided. This control should be performed according to the maximum transmission power of the MS $P_{t, i_{-} \max }$ and the maximum pathloss $L_{i_{-} \max }$, thus obtaining a maximum permissible cell loading factor
$\eta_{U L_{-} \max }$.Therefore, the mobile station maximum transmission power is :

$$
\begin{gathered}
L_{i_{-} \max } \frac{P_{N}}{\left(\frac{W}{\left.\frac{E_{b}}{N_{0}}\right)_{i} R_{i} v_{i}}+1\right)\left(1-\eta_{U L_{-} \max }\right)}
\end{gathered}
$$

Thus:

$$
\eta_{U L_{-} \max }=1-\frac{P_{N}}{P_{t, i_{-} \max }} \frac{L_{i_{-} \max }}{\frac{W}{\left.\frac{E_{b}}{N_{0}}\right)_{i} R_{i} v_{i}}+1}
$$

The previous equations illustrate the tradeoff between coverage and capacity. On the other hand, the cell loading factor in Uplink limits the maximum allowable pathloss as shown in the following equation [1]:

$$
\begin{aligned}
& L_{i_{-} \max }= \\
& \frac{P_{t, i_{-} \max }}{P_{N}}\left[\frac{W}{\left.\frac{E_{b}}{N_{0}}\right)_{i} R_{i} v_{i}}+1\right]\left(1-\eta_{U L}\right)
\end{aligned}
$$

\subsection{Mobile Station Transmission Power in the Case of Multiple Cells}

To investigate the Uplink capacity in the case of multiple cells, we will treat the above equations by introducing other-cell interferences caused by neighboring cells. [1]. Thus, the expression of $E_{b} / N_{0}$ becomes:

$$
\left.\frac{E_{b}}{N_{0}}\right)_{i}=\frac{W}{R_{i}} \cdot \frac{P_{r, i}}{P_{N}+\left(1+f_{U L}\right) P_{o w n}-P_{r, i}}
$$

And:

$$
P_{t o t}=P_{N}+\left(1+f_{U L}\right) P_{o w n}
$$

Where :

$$
f_{U L}=\frac{P_{o t h e r}}{P_{o w n}}=\frac{\sum_{j=1}^{N} P_{r, j}}{\sum_{i=1}^{N} P_{r, i}}
$$


Is the other-to-own-cell interference and $P_{\text {other }}$ is the total received power from users connected to neighboring cells. Consequently, Node B received power from the user $(i)$ becomes:

$$
P_{r, i}=\frac{P_{N}+\left(1+f_{U L}\right) P_{o w n}}{\frac{W}{\left.\frac{E_{b}}{N_{0}}\right)_{i} R_{i} v_{i}}+1}
$$

Therefore, the total own-cell interferences received power at the Node B is rewritten as:

$$
P_{\text {own }}=\frac{P_{N} \sum_{i=1}^{N} \frac{1}{1-\left(1+f_{U L}\right) \sum_{i=1}^{N} \frac{\left.\frac{W}{E_{0}}\right)_{i} R_{i} v_{i}}{\left.\frac{E_{b}}{N_{0}}\right)_{i} R_{i} v_{i}}+1}}{1}
$$

Then, the final expression of $P_{r, i}$ in the case of several cells is expressed as :

$$
\begin{aligned}
& P_{r, i}= \\
& \frac{P_{N}}{\left(\frac{W}{\left.\frac{E_{b}}{N_{0}}\right)_{i} R_{i} v_{i}}+1\right)\left(1-\left(1+f_{U L}\right) \sum_{i=1}^{N} \frac{1}{\frac{W}{\left.\frac{E_{b}}{N_{0}}\right)_{i} R_{i} v_{i}}+1}\right)}
\end{aligned}
$$

Therefore, the mobile station required transmission power is:

$$
\begin{aligned}
& P_{t, i}= \\
& L_{i} \frac{P_{N}}{\left.\frac{W}{\left.\frac{E_{b}}{N_{0}}\right)_{i} R_{i} v_{i}}+1\right)\left(1-\left(1+f_{U L}\right) \sum_{i=1}^{N} \frac{1}{\frac{W}{\left.\frac{E_{b}}{N_{0}}\right)_{i} R_{i} v_{i}}+1}\right)}
\end{aligned}
$$

\subsubsection{Uplink cell capacity and Noise Rise expressions in the case of multiple cells}

In the case of multiple cells, the cell loading factor expression is:

$$
\eta_{U L}=\left(1+f_{U L}\right) \sum_{i=1}^{N} \frac{1}{\frac{W}{\left.\frac{E_{b}}{N_{0}}\right)_{i} R_{i} v_{i}}+1}
$$

From this equation, we can note that the cell loading factor, in the case of multiple cells, depends on the factor $f_{U L}$, the number of users in the cell and the type of service. The Uplink cell loading factor must verify the following condition:

$$
\sum_{i=1}^{N}\left(1+f_{U L}\right) \frac{1}{\frac{W}{\left.\frac{E_{b}}{N_{0}}\right)_{i} R_{i} v_{i}}+1}<1
$$

Thus, the Uplink capacity is limited to the following inequality:

$$
N<\left(\frac{W}{\left.\frac{E_{b}}{N_{0}}\right)_{i} R_{i} v_{i}}+1\right)\left(\frac{1}{1+f_{U L}}\right)
$$

The Uplink capacity is the maximu m number of users when the cell loading factor has reached its maximum value. Therefore:

$$
N_{\text {Max }}=\left(1+\frac{W}{\left.\frac{E_{b}}{N_{0}}\right)_{i} R_{i} v_{i}}\right)\left(\frac{\eta_{U L_{-} \max }}{1+f_{U L}}\right)
$$

From (27), the Noise Rise expression is given as:

$$
N R=\frac{1}{1-\left(1+f_{U L}\right) \frac{N}{1+\frac{W}{\left.\frac{E_{b}}{N_{0}}\right)_{i} R_{i} v_{i}}}}
$$

\subsubsection{Capacity and coverage trade-off in the case of multiple cells}

Similarly to the case of an isolated cell, the maximum allowable path loss is given by: 
$L_{i_{-} \max }=\frac{P_{t, i_{-} \max }}{P_{N}}\left[\frac{W}{\left.\frac{E_{b}}{N_{0}}\right)_{i} R_{i} v_{i}}+1\right]\left(1-\eta_{U L}\right)$

Where $\eta_{U L}$ is expressed in (27).

\section{Admission control algorithms}

\subsection{The Effect of Admission Control on Uplink Capacity}

In Uplink, we are interested on two admission control algorithms. The first one is based on the cell loading factor $\eta_{U L}[5,7,10-11]$, presented in (12) in the case of an isolated cell and in (27) in the case of multiple cells.

Assuming there are $\mathrm{N}$ users simultaneously active in the cell, the $(N+1)$ th request will be accepted if the following condition is satisfied:

$$
\eta_{U L}+\Delta \eta \leq \eta_{U L_{-} \max }
$$

$\eta_{U L}$ is the cell loading factor measured during a period $\mathrm{T}$ where $N$ users are active. $\Delta \eta$ is the cell loading factor increase due to the $(N+1)$ th user. $\eta_{U L_{-} \text {max }}$ is the maximum cell loading factor. In the case of an isolated cell $\Delta \eta$ |parameter is expressed by:

$$
\Delta \eta=\frac{1}{\frac{W}{\left.\frac{E_{b}}{N_{0}}\right)_{N+1} R_{N+1} v_{N+1}}+1}
$$

And in the case of multiple cells, $\Delta \eta$ becomes:

$$
\Delta \eta=\frac{\left(1+f_{U L}\right)}{\frac{W}{\left.\frac{E_{b}}{N_{0}}\right)_{N+1} R_{N+1} v_{N+1}}+1}
$$

The goal of admission control is to ensure good quality of service for the new request as well as for connections already established. If $\eta_{U L}+\Delta \eta>\eta_{U L_{-} \max }$, an unstable situation is brought about, in form of cuts in some existing communications, caused by the high level of interference in the cell.

The second method of admission control in Uplink is based on the NR factor $[5,6,8,9]$. We denote by $N R_{\text {new }}$ the Noise Rise calcu lated after the admission of the new request, and by $N R_{\max }$, the maximum Noise Rise set by the operator in the dimensioning phase. To avoid the overloading situation, the following constraint must be satisfied:

$$
N R_{\text {new }} \leq N R_{\max }
$$

\subsection{Freeing Resources Algorithm}

The aim of this algorithm is to reduce the interferences level taking place in the overloaded cells, by asking mobile stations located in the handover area to stop communicating with them.

When a cell is in an overloading situation, the Node $\mathrm{B}$ initiates the process of Freeing Resources $(F R)$ in order to be able to accept the new request. In fact, when a MS appears in the cell, the cell loading factor increases with $\Delta \eta$. When the new load exceeds the maximum value, the Node $B$ initiates the $F R$ mechanis $m$ in order to alleviate the load. Consequently two situations will be presented:

1- If no MS is in the overlapping area, the mechanism will be unable to release the radio resources in the overloaded cell and therefore the new request will be rejected.

2- If there are mobile stations in the overlapping area and if the call is disconnected with some of them, the Node B in the overloading cell recalculates the new load by estimating the cell load factor increase due to new request, to see if the admission constraint is checked to accept the new request. Otherwise the request is rejected.

\subsection{The proposed Algorithm}

Let Start with an empty network. Users are added to the system until the target value of the initial cell loading factor is reached. When a new request arrives, the admission control algorithm decides whether the user will be accepted or not based on the new estimated load. If the load is less than or equal to the maximum cell loading factor, the user is accepted. If the network is already overloaded, the system searches if there are mobile stations in handover areas. If the overlapping area contains no mobile station, the new user is rejected. If there is a mobile station in handover situation, the system cuts off its communication with the overloaded cell and the number of simultaneously active users in the cell is reduced. If (33) is satisfied, the call is accepted, otherwise it is rejected. The following diagram summarizes the algorithm described above: 


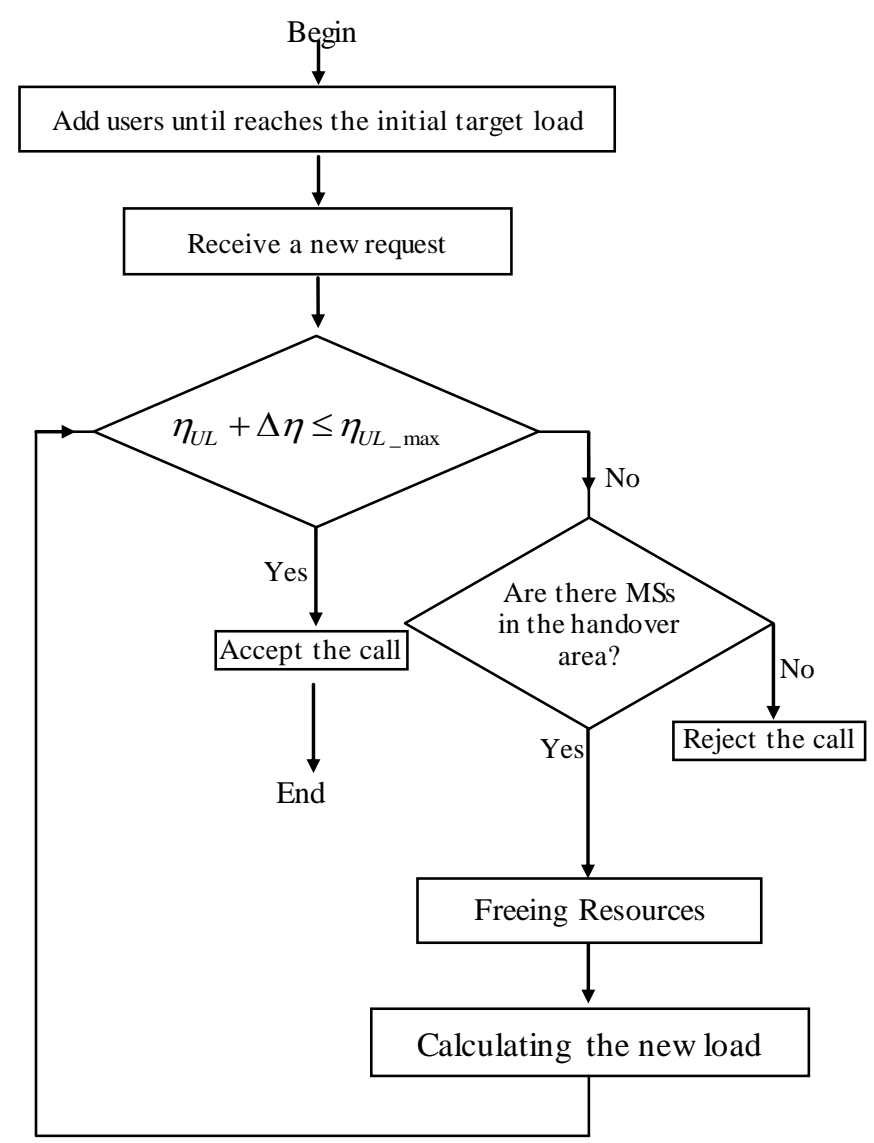

Fig. 1: Freeing Resource algorithm

\section{Simulation Parameters}

The simulation parameters taken into account are listed in the table bellow [1]:

Table 1: Simulation parameters

\begin{tabular}{|c|c|}
\hline Parameters & Values \\
\hline$W$ (chip rate) & $3.84 \mathrm{Mcps}$ \\
\hline$R$ (voice) & $12.2 \mathrm{kbps}$ \\
\hline$R$ (data) & $64 \mathrm{kbps}$ \\
\hline$E_{b} / N_{0}$ (voice) & $5 \mathrm{~dB}$ \\
\hline$E_{b} / N_{o}$ (data) & $3 \mathrm{~dB}$ \\
\hline$v$ (voice) & 0.67 \\
\hline$v$ (data) & 1 \\
\hline$f u l$ & 0.67 \\
\hline$P_{t, i \_m a x}$ & $125 \mathrm{Mw}$ \\
\hline
\end{tabular}

Fig. 2 shows that, if the cell loading factor increases, the coverage decreases and inversely, resulting in the phenomenon of cell respiration.

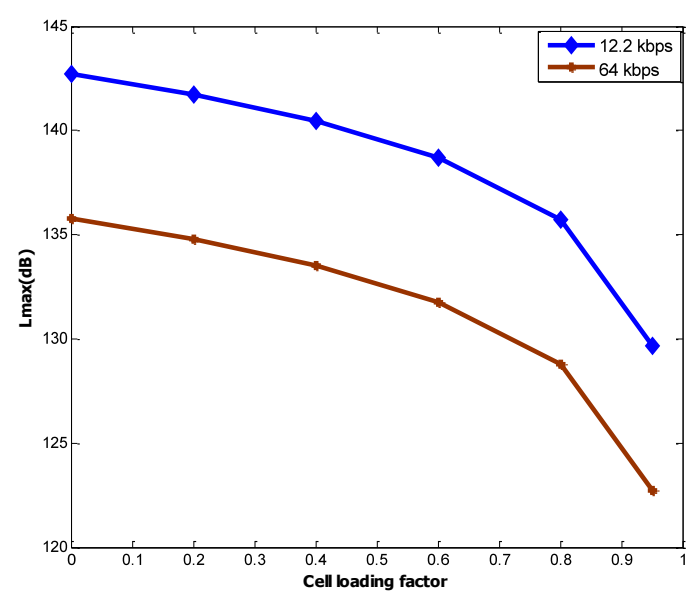

Fig. 2: Maximum coverage as a function of $\eta_{D L}$

In addition, we notice that, the higher the bit rate is, the weaker the coverage becomes, which is due to the increase in transmission power need of the MS.

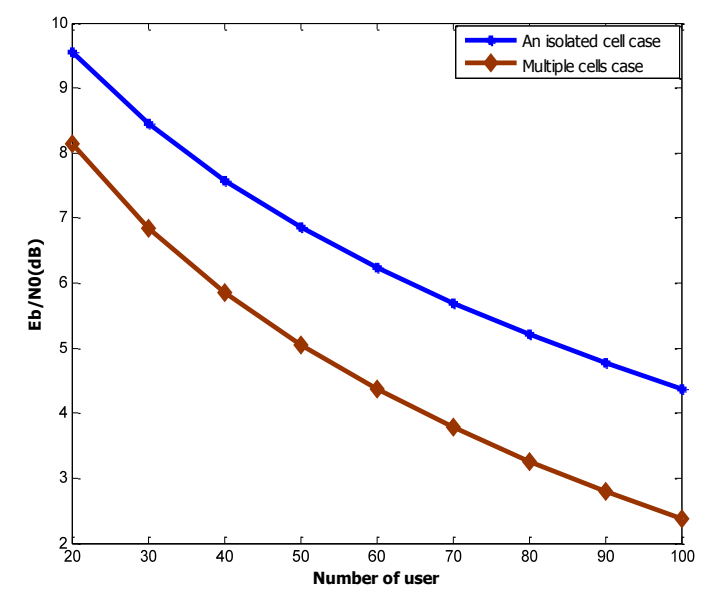

Fig. 3: $E_{b} / N_{0}$ as a function of number of users

From Fig. 3, we note that in the case of a single cell, we can accept up to 85 users activating the voice service, while in the case of multiple cells, we can only accept 50 users. Therefore we can conclude that the presence of other-cell interferences adversely affect the capacity. 


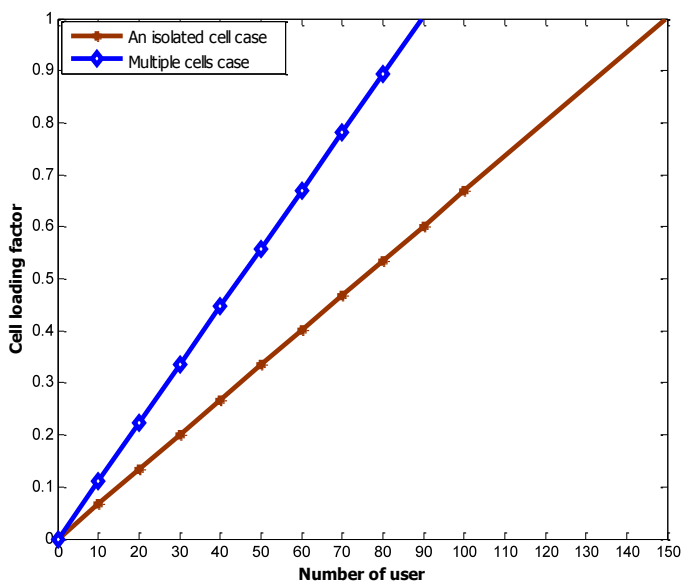

Fig. 4: Cell loading factor in the case of voice service

From Fig. 4, we see that if $\eta_{\mathrm{UL}_{-} \max }=0.6$, the maximum number of users activating voice that a cell can support, in the case of an isolated cell, is approximately 90 users, while in the case of multiple cells, the maximum number of users supported is approximately equal to 54 .

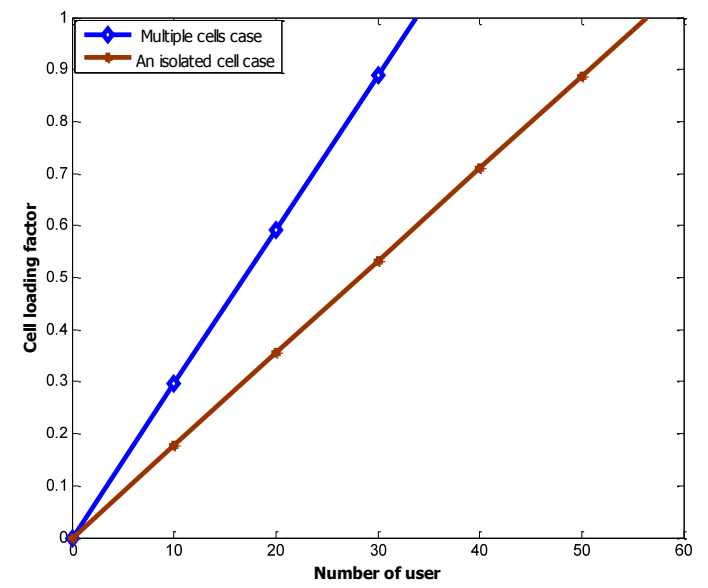

Fig. 5: Cell loading factor in the case of voice/ data

In the case of two services: voice and data, Fig. 5 shows that, for $\eta_{\mathrm{UL}_{-} \max }=0,6$ the maximum number of users supported in the case of an isolated cell is approximately 34 users, while in the case of multiple cells, the number of users supported is approximately 20. In addition, according to the two figures, for a given value of maximum cell loading factor, we note that, the maximu m cell capacity supported by the cell in the case of multi-service network is lower than that supported by a cell activating voice, in the two studied scenarios.

The following figure shows the variation of $N R$ as a function of simultaneously active users, in the case of voice and in the case of two services: voice/ data, for two different scenarios.:

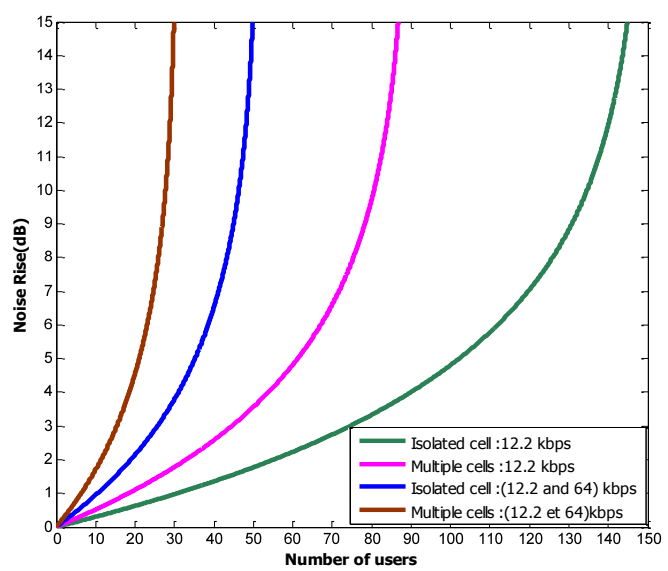

Fig. 6: Noise Rise factor as a function of the number of users

From this figure, we note that the Noise Rise factor increases with the number of simultaneously active users in the cell. In fact, for $N R_{-\max }=4 \mathrm{~dB}$, corresponding to the maximum cell loading factor $\eta_{\mathrm{UL}_{-} \max }=0,6$, we notice the same results found in Fig. 5 and Fig. 6. Therefore the operator is based on one of these two parameters to determine the maximum capacity that can support a cell.

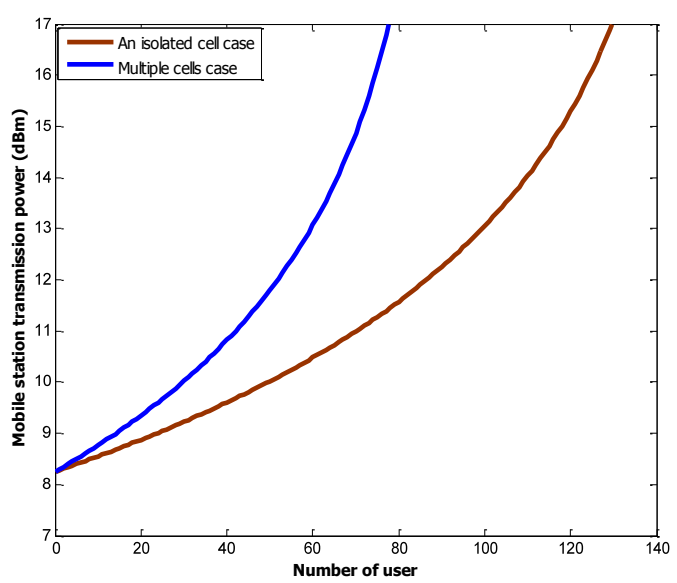

Fig. 7: Mobile station transmission power in the case of voice service



Fig. 8: Mobile station transmission power in the case of voice/ data services 
From Fig. 7 and Fig. 8 we note that, for the same number of simultaneously active users in the cell, the mobile station required transmission power in the case of an isolated cell, is lower in comparison with that required in the case of multiple cells. The value of this power in the case of $64 \mathrm{kbps}$ data rate, for a very small number of users, is higher than in the case of $12.2 \mathrm{kbps}$ data rate. In addition, the difference in power requirement between the two scenarios increases when the number of users in the cell becomes important. This is explained by the increase in interference level received at the Node B, which seeks a high power level to achieve the desired signal quality.

Consider a $3 \mathrm{G}$ network already containing 62 users activating voice, where $\eta_{\mathrm{UL}_{-} \max }=0,7$. The variation of the blocking probability as a function of the new requests in the case of the multiple cells case is shown in the following figure:

From this figure, we see that the blocking probability increases significantly with the number of new requests seeking access to the cell.

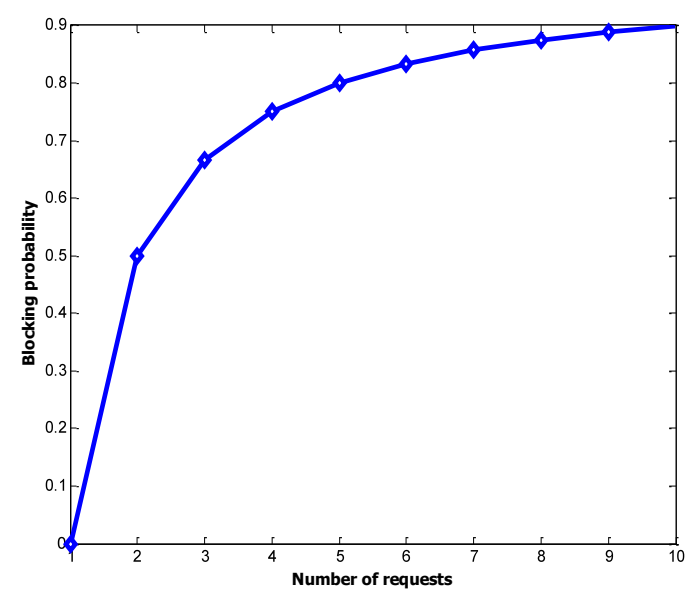

Fig. 9: Blocking probability as a function of new requests

Fig. 10 shows the blocking probability obtained by using the $F R$ algorithm, with liberation of 1,2 and 3 mobile stations activating voice, in the case of new requests of $12.2 \mathrm{kbps}$.

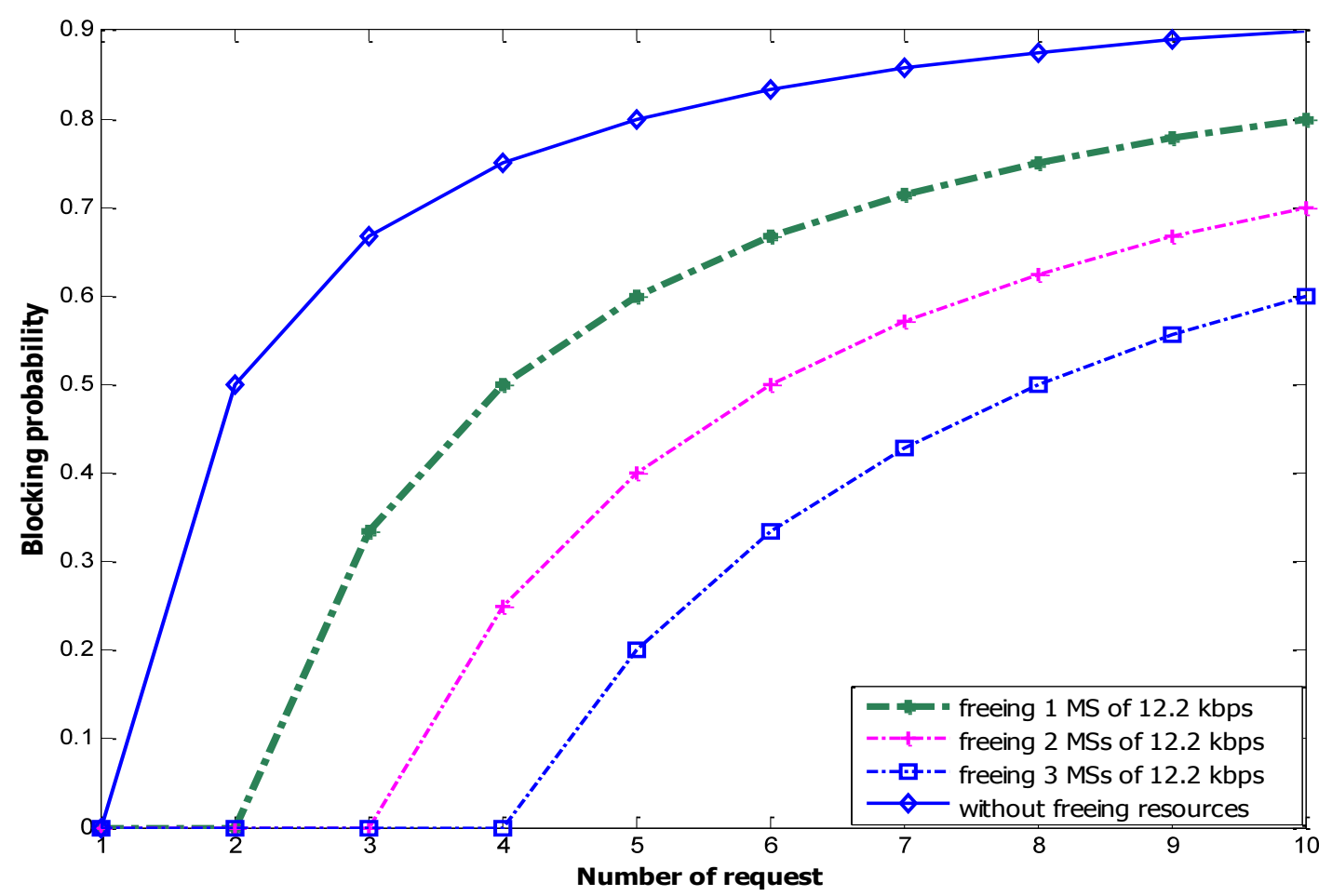

Fig. 10: Blocking probability as a function of new requests in the case of releasing 1,2 and 3 MSs of $12.2 \mathrm{kbps}$ in the case of voice

From this figure, the blocking probability of new requests of $12.2 \mathrm{kbps}$, decreases with the number of released mobile stations, activating the voice service.

Fig. 11 and Fig. 12 show respectively, the blocking probability of new requests of $12.2 \mathrm{kbps}$, in a multiservice network, in the case of liberation of 1,2 and 3 mobile stations of $12.2 \mathrm{kbps}$ data rate, and in the case of liberation of a single MS of $64 \mathrm{kbps}$ data rate. 


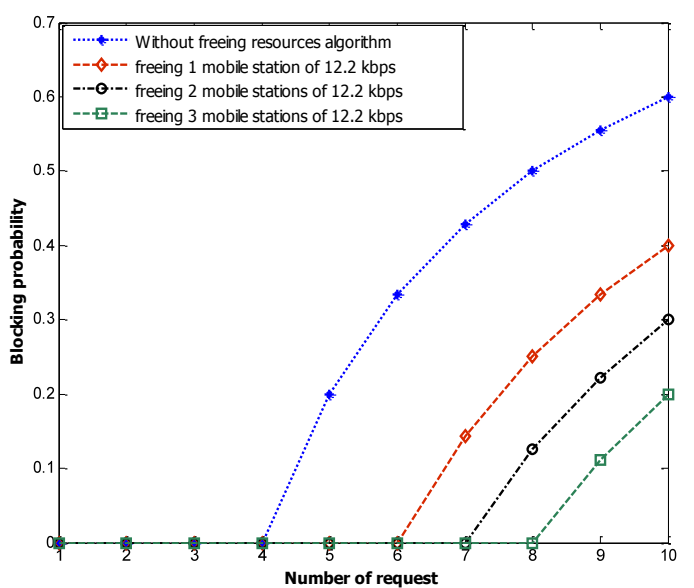

Fig. 11: Blocking probability as a function of new requests in the case of releasing 1, 2 and $3 \mathrm{MSs}$ of $12.2 \mathrm{kbps}$ in the case of voice/ data

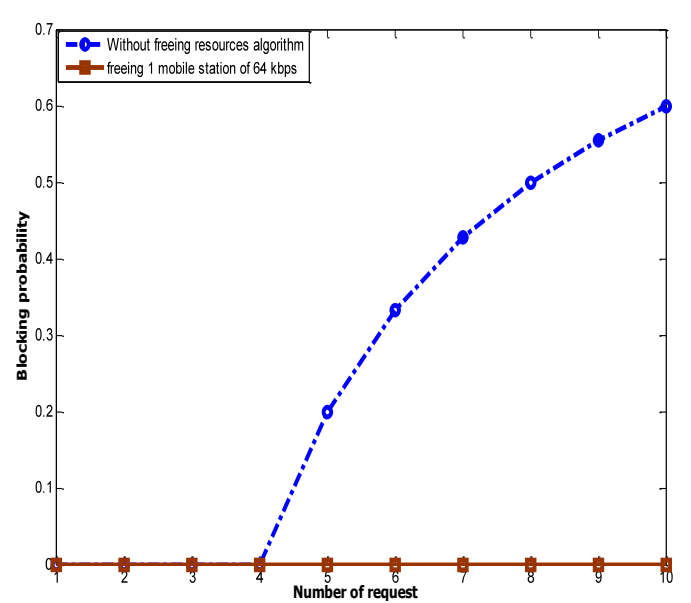

Fig. 12: Blocking probability as a function of new requests in the case of releasing one MS of $64 \mathrm{kbps}$ in the case of voice

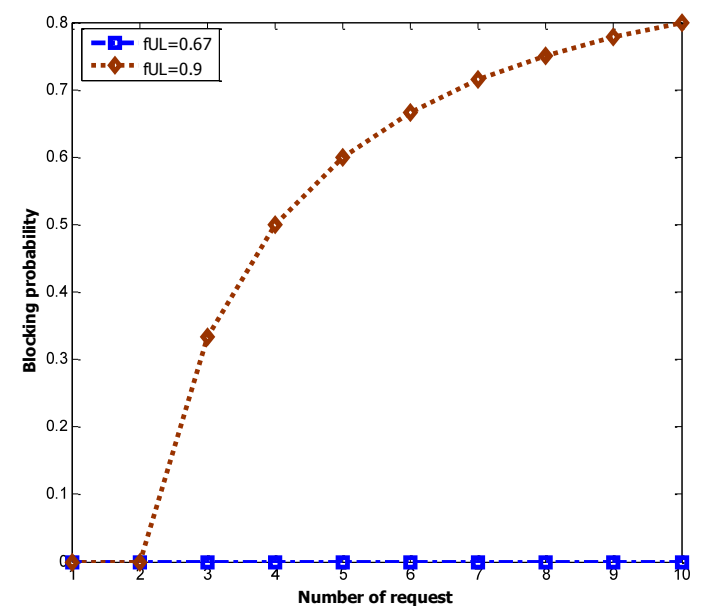

Fig. 13: Blocking probability as a function of new requests in the case of releasing one MS of $64 \mathrm{kbps}$ for two values of $f_{U L}$

From Fig. 11, the release of three mobile stations activating voice cancels the blocking probability for a number of requests less than or equal to 8 , and decreases it considerably when it exceeds 8 requests in comparison with the case of releasing 1 and 2 MSs activating voice.

From Fig. 12, we note that, releasing a single MS of $64 \mathrm{kbps}$, cancels the blocking probability even for 10 requests.

In Fig. 13, we represent the variation of blocking probability according to the number of new requests of $12.2 \mathrm{kbps}$ in the case of an isolated cell, and in the case of multiple cells for two values of other-to-own-cell interference factor.

We note that the blocking probability for $f_{U L}=0.9$ is very high, while that obtained with $f_{U L}=0.67$, for a number of requests ranging from 1 to 10 , is null. According to these results, we conclude that the high interference level caused by neighboring cells increases the blocking probability of new requests.

\section{Conclusion}

In this work, we studied the effect of other-to-own-cell interference on the WCDMA cell uplink capacity, in the case of voice and in the case of two services: voice and data of $64 \mathrm{kbps}$. We are interested on two different scenarios: an isolated cell and multiple cells. We have shown that the maximum capacity obtained in the case of an isolated cell is approximately twice that obtained in a scenario of multiple cells. Then, we demonstrated that the required transmission power for mobile station in the case of an isolated cell is lower than that obtained in the case of multiple cells.

In addition, we proposed a Freeing Resources algorithm that is based on stopping communication of some mobile stations located in the handover area, with the overloaded cell, taking advantage of the multiple connections that the MS establishes with Node Bs serving the overlapping area. From the results obtained, we found that the release of canal of a single MS of 64 kbps data rate cancels the blocking probability of new applications, which demonstrates the effectiveness of this algorithm for an interval from 1 to 10 requests. In addition, we found that a high value of other-to-own cell interference increases the blocking probability of new requests and thus limits the Uplink capacity.

\section{References}

[1] Jordi Pérez-Romero, Oriol Sallent, Ramon Agusti, Radio Resource Management Strategies In UMTS, All of Universitat Polite 'cnica de Catalunya (UPC), Spain, Miguel Angel Diaz-Guerra Telefonica Moviles Espana, S.A., Spain.

[2] Settapong Malisuwan et al., Uplink Capacity of mobile all-packet-service WCDMA Internet 
systems in emi environ ment, Proc. IEEE Int. Sy mp. Electromag. Compat, Japan, 2004.

[3] José Outes Carnero, Up link Capacity Enhancement in WCDMA, Multi Cell Admission Control, Synchronised Schemes and Fast Packet Scheduling, ISBN 87-90834-54-2, ISSN 0908-1224, R041011, Department of Communication Technology, Institute of Electronic Systems, Aalborg University, Niels Jernes,, March 2004.

[4] Thrasivoulos (Sakis) Griparis, Tristan Lee, The capacity of WCDMA network: With box study, Bechtel Telecommunications Technical Newspaper, vol. 3, No 1, august 2005.Texas Wireless Symposium 2005.

[5] Zdeněk RŮŽIČKA, Stanislav HANUS, Admission Control And Load Control In UMTS Network, Institute of Radio Electronics, Brno University of Technology Purkyňova 118, 61200 Brno, Czech Republic .

[6] Erik Geijer Lundin, Uplink Admission Control Based on Estimated Interference in WCDMA Systems, Master's Thesis completed at Communication Systems,Lin köpings Universitet, Sweden.

[7] Salman Al-Qahtani and Ashraf Mahmoud, Uplink Admission Control in WCDMA, International Symposium on Wireless Communications (ISWSN'05) 2005.

[8] Thamer Al-Meshhadany, The impact of Soft handoff on the Uplink capacity in WCDMA systems Thamer Al-Meshhadany, Computer Communications 29 (2006) 3804-3811.

[9] S. A. El-Dolil, A. Y. Al-nahari, M. I. Desouky and F. E. Abd El-samiem Uplink Power Based Admission Control In Multi-Cell WCDMA Network W ith Heterogeneous Traffic, Progress In Electromagnetics Research B, Vol. 1, 115-134, 2008, Department of Electronics and Electrical Communications Faculty of Electronic Engineering Menoufia University Menouf, Egypt.

[10] Rachod Patachaianand, Kumbesan Sandrasegaran, Simulation of Call Admission Control in MultiTraffics WCDMA System, Institute of In formation and Communication Technologies and Faculty of Engineering, University of Technology Sydney (UTS).

[11] Abdullah Al Muzahid, Ahmed Khurshid, Md. Mostofa Ali Patwary, Md. Mostofa Akbar, Reservation Based Adaptive Uplink Admission control for WCDMA, Department of CS of CS
Faculty of Science and Technology in Tangier Morocco in 2004 and the Desa degree in Telecommunications System from Faculty of Science of Tetuan in November 2006 and is currently pursuing the Ph.D.degree.

His research interests are third-generation mobile system design, radio network planning, and optimization. She is an IEEE student member since 2006.and a member of IAM operator project science 2007.

Noura AKNIN, received the Licence in Physics and the $\mathrm{PhD}$ degree in Electrical Eng ineering, respectively, in 1988 and 1998 from Abdelmalek Essaadi University in Tetouan, Morocco. She is a Professor of Telecommunications and Computer Engineering in Abdelmalek Essaadi University since 2000. She is the Co-founder of the IEEE Morocco Section since November 2004. She has been a member of the Organizing and the Scientific Committees of several symposia and conferences dealing with RF, Mobile Networks, Social Web and information technologies. Prof Noura AKNIN is a member of IEEE Communications Society and Computer Society. Her research interests focus mainly on Wireless and mobile communication systems, radio network planning and optimization.

\begin{abstract}
Ahmed EL MOUSSAOUI, received the PhD degree in electronics at the university of BRADFORD in 1990. In 2007 he received the international master in E-learning in the Curt Bosh institute in Switzerland. He has been a member of the Organizing and the Scientific Committees of several symposia and conferences dealing with RF, Mobile Networks and information technologies. He has participated in several project with France and spain. His research interests are: electronic engineering, third generation mobile system, radio network planning and optimization.
\end{abstract}

How to cite this paper: Fadoua Thami Alami, Noura Aknin, Ahmed El Moussaoui,"Uplink Capacity Estimation and Enhancement in WCDM A Network", International Journal of Information Technology and Computer Science(IJITCS), vol.5, no.9, pp.21-30, 2013. DOI: 10.5815/ijitcs.2013.09.02

\author{
Authors' Profile \\ Fadoua THAMI ALAMI, received the licence in \\ computer science from Abdlmelek Essaidi university,
}

